\title{
A Rare Case of Bilateral Peritonsillar Abscess in a Child: An Impending Deadly Condition
}

\author{
Rajarajeswari Arunathan, ${ }^{1}$ (1) Shi Nee Tan²
}

'Department of Otorhinolaryngology - Head and Neck Surgery, Hospital Lahad Datu, Lahad Datu, Sabah, Malaysia.

${ }^{2}$ Department of Otorhinolaryngology - Head And Neck Surgery, Kpj University College, Kota

Seriemas, Negeri Sembilan, Malaysia

\section{ABSTRACT}

Peritonsillar abscess (PTA) is one of the deep neck infections. Unilateral PTA is more common than bilateral PTA and is more common in adults than children. Therefore, it is a rare condition with a low rate of incidence. To the best of our knowledge, the literature on this topic (bilateral PTA in children) is limited with this manuscript. In this study, we present a 5-year-old girl who presented with sore throat, odynophagia, and loss of appetite for two weeks, and fever for one week. On clinical examination, a bilateral enlarged tonsil with grade III-IV right tonsil, and grade III left tonsil was observed, respectively. The right tonsil is more erythematous, bulging, and exudative compared to the left tonsil, with the uvula centrally placed. The patient underwent bilateral incision and drainage under general anesthesia followed by intravenous antibiotics for one week. This case report highlighted the need for a high level of clinical suspicion to reach a prompt diagnosis. The management of the airway, which would be difficult, is an important aspect of the treatment. Thus, an immediate rapid drainage is required as much as an emergency surgical intervention to avoid unwanted morbidity and mortality.

Keywords: Cellulitis, child, fine-needle aspiration, peritonsillar abscess

\section{INTRODUCTION}

Peritonsillar space is an area bounded by palatine tonsillar capsule medially, superior constrictor laterally, palatoglossus muscle (anterior pillar) anteriorly and palatopharyngeus muscle (posterior pillar) posteriorly. Peritonsillar abscess (PTA), known as quinsy, is defined as an accumulation of pus within the space described above. Unilateral PTA is more common than bilateral PTA and is more common in adults than children. ${ }^{[1]}$ The incidence rate of bilateral PTA is unknown; in reports involving quinsy tonsillectomy with contralateral abscess during the procedure itself, it was seen at the rate of $1.9 \%$ to $24 \%{ }^{[2]}$ The incidence of PTA alone in children is about 14 to 30 cases per $100.000 .{ }^{[3]}$ To the best of our knowledge, the literature review on this topic (bilateral PTA in children) is very limited.

We present a rare bilateral PTA in a child and highlight the need for a high level of clinical suspicion to reach a prompt diagnosis.

\section{CASE REPORT}

A 5-year-old girl presented with two-weeks history of sore throat, odynophagia, and loss of appetite. Her condition was aggravated by a week-long fever with an inability to fully open her mouth, drooling, and a muffled "hot potato" voice. There were no breathing difficulty, no 
history of foreign body ingestion or neck swelling. Clinical examination documented that she has multiple spiking fever $38^{\circ} \mathrm{C}$ along with the other normal vital signs. She was not tachycardic and her blood pressure was $100 / 60 \mathrm{mmHg}$. She had bilateral enlarged tonsils of grade IV size in her oral cavity. Located centrally to the uvula the right tonsil was more erythematous, bulging, and exudative compared to the left tonsil. Figure 1 shows right tonsil is more erythematous, bulging and exudative compared to the left tonsil, with uvula centrally placed. Further examination was unable to proceed as the child was uncooperative.

Her laboratory results showed an increase in white cell count with normal electrolytes. Table 1 shows the laboratory results of the patient on arrival to the emergency de-

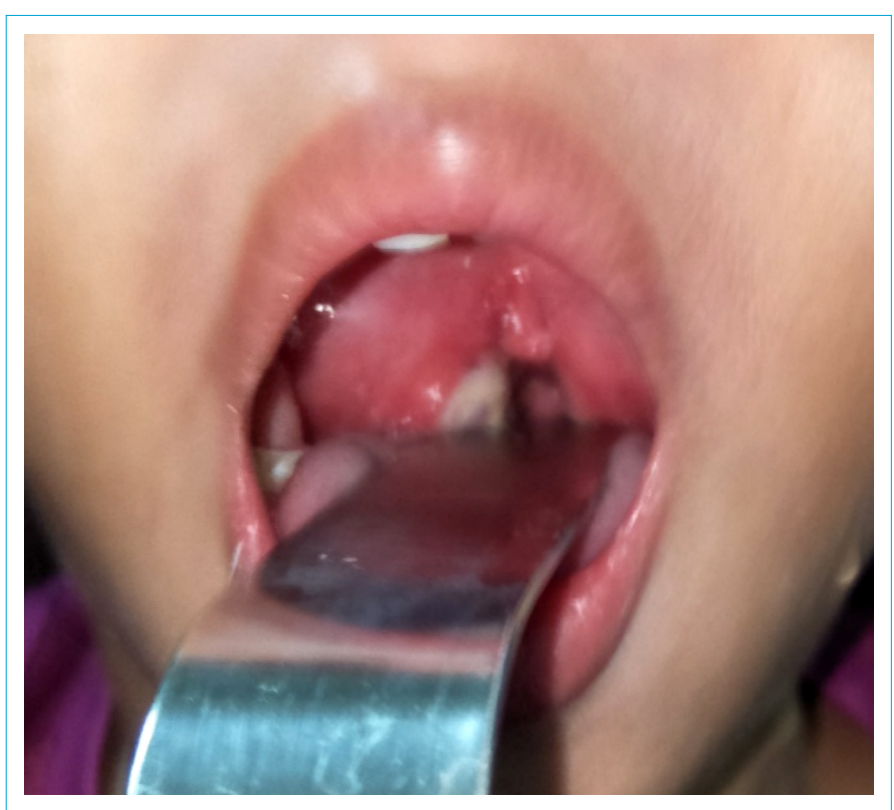

Figure 1. Right tonsil of the patient.

\begin{tabular}{|c|c|}
\hline & Results (Reference values) \\
\hline Haemoglobin (g/dl) & $10.2(10.0-14.0)$ \\
\hline White cell count $\left(10^{9} / \mathrm{L}\right)$ & $20.0(6.00-15.00)$ \\
\hline Platelets $\left(10^{9} / \mathrm{L}\right)$ & $200.0(150.0-450.0)$ \\
\hline Neutrophils (\%) & $86.0(40.0-80.0)$ \\
\hline Lymphocytes (\%) & $20.0(20.0-40.0)$ \\
\hline Urea (mg/dL) & $14.0(1.7-8.3)$ \\
\hline Creatinine (mg/dL) & $1.0(0.6-1.2)$ \\
\hline Sodium (mmol/L) & $136.0(137.0-148.0)$ \\
\hline Potassium (mmol/L) & $4.5(3.5-5.1)$ \\
\hline Chloride (mmol/L) & 105 (98.0-107.0) \\
\hline
\end{tabular}

partment. Patient has neutrophil predominant white cells with normal electrolytes. A provisional diagnosis of bilateral PTA was made. Since there was a risk of impending upper airway obstruction, especially in a child, the patient was rushed to the operation theatre to secure the airway. Intubation was successfully performed using non-resistant glidescope-guided intubation. Following the aspiration of bilateral peritonsillar area at the most bulging area confirming the diagnosis, incision and drainage were performed at the superior portion of both anterior pillars. Figure 2 shows the picture of post incision and drainage at the superior portion of both anterior pillars.

She was intubated for 24 hours because of packing over the intraoral packing of the bilateral incision site. Her postoperative condition improved dramatically. Intravenous Augmentin $1.2 \mathrm{~g}$ and Metronidazole $500 \mathrm{mg}$ three times daily were started for one week. She responded very well after the surgery. She was reassessed after a week and showed a wellresolved infection with no signs of recurrence within a year.

\section{DISCUSSION}

PTA is a common complication of tonsillitis. Since the tonsillitis is an infection involving different developmental stages abscesses on respective sides of both tonsils, the progression of PTA occurs bilaterally. ${ }^{[4]}$

There are two main hypotheses regarding the pathogenesis of PTA. The first and the most widely accepted theory is that bacterial tonsillitis progresses to abscess formation. Another hypothesis is that there is an infection of the minor



Figure 2. Post incision and drainage of patient. 
salivary gland specifically Weber's glands..$^{[5-7]}$

It may be difficult to diagnose bilateral PTA clinically due to different diagnoses such as lymphoma, infectious mononucleosis, severe acute bacterial tonsillitis, or major salivary gland mass. ${ }^{[2,8,9]}$ Therefore, advocating the need for contrast-enhanced computed tomography (CT) imaging may help diagnosis, especially in the absence of inflammatory findings. ${ }^{[9,}{ }^{10]}$ Moreover, it may help identify other complications such as deep neck space infection. ${ }^{[2,10]}$

However, in our case, CT imaging was not performed as we believed that the diagnosis of bilateral PTA in the child should be kept in mind that the impending upper airway obstruction may be a nightmare. The treatment of PTA usually consists of systemic antibiotics followed by pus drainage. ${ }^{[9,10]}$ After the airway became safe, needle aspiration was performed on our patient for diagnostic purposes, and then definitive treatment was applied through incision and drainage with the simultaneous administration of intravenous antibiotics. Incision and drainage were done using a blunt scalpel to incise the peritonsillar region and to promote drainage of the abscess. The incision site was packed to prevent re-accumulation of pus and to allow complete pus drainage.

\section{CONCLUSION}

Bilateral PTA is an emergency condition, especially in children. This should warrant a high index suspicion, as the delay can lead to severe airway obstruction and undesired scenario.

\section{Disclosures}

Informed Consent: Written informed consent was obtained from the parents of the patient for the publication of the case report and the accompanying images.

Conflict of Interest: None.

Peer-review: Externally peer-reviewed.
Authorship contributions: Concept - R.A.; Design - R.A., T.S.N.; Supervision - T.S.N.; Materials - R.A., T.S.N.; Data collection \&/or processing - R.A., T.S.N.; Literature search - R.A., T.S.N.; Writing R.A., T.S.N.; Critical Review - T.S.N.

\section{REFERENCES}

1. Seerig MM, Chueiri L, Jacques J, de Mello MFPC, da Silva MBC, Zatt DB, et al. Bilateral Peritonsillar Abscess in an Infant: An Unusual Presentation of Sore Throat. Case Rep Otolaryngol 2017;2017:4670152. (CrossRef)

2. Lin YY, Lee JC. Bilateral peritonsillar abscesses complicating acute tonsillitis. CMAJ 2011;183(11):1276-9. (CrossRef]

3. Kim DK, Lee JW, Na YS, Kim MJ, Lee JH, Park CH. Clinical factor for successful nonsurgical treatment of pediatric peritonsillar abscess. Laryngoscope 2015;125(11):2608-11. (CrossRef]

4. Papacharalampous GX, Vlastarakos PV, Kotsis G, Davilis D, Manolopoulos L. Bilateral Peritonsillar Abscesses: A Case Presentation and Review of the Current Literature with regard to the Controversies in Diagnosis and Treatment. Case Rep Med 2011;2011:981924. (CrossRef]

5. Galioto NJ. Peritonsillar Abscess. Am Fam Physician 2017;95(8):501-6.

6. Klug TE, Rusan M, Fuursted K, Ovesen T. Peritonsillar Abscess: Complication of Acute Tonsillitis or Weber's Glands Infection? Otolaryngol Head Neck Surg 2016;155(2):199-207. (CrossRef]

7. Mazur E, Czerwińska E, Korona-Głowniak I, Grochowalska A, Kozioł-Montewka M. Epidemiology, clinical history and microbiology of peritonsillar abscess. Eur J Clin Microbiol Infect Dis 2015;34(3):549-54. (CrossRef]

8. Mobley SR. Bilateral peritonsillar abscess: case report and presentation of its clinical appearance. Ear Nose Throat $J$ 2001;80(6):381-2. (CrossRef]

9. Schraff S, McGinn JD, Derkay CS. Peritonsillar abscess in children: a 10-year review of diagnosis and management. Int $J$ Pediatr Otorhinolaryngol 2001;57(3):213-8. (CrossRef]

10. Al Awadh I, Aldrees T, AlQaryan S, Alharethy S, AlShehri H. Bilateral peritonsillar abscess: A case report and pertinent literature review. Int J Surg Case Rep 2017;36:34-7. (CrossRef] 